\title{
Políticas agrarias, Seguridad Alimentaria y Nutricional y Soberanía Alimentaria: luces y sombras del caso cubano (1990-2015)
}

\section{Elisa Botella Rodríguez}

Departamento de Economía e Historia Económica. Instituto de Iberoamérica, Universidad de Salamanca, España ebotella@usal.es

Cita sugerida: Botella Rodríguez, R. (2018). Políticas agrarias, Seguridad Alimentaria y Nutricional y Soberanía Alimentaria: luces y sombras del caso cubano (1990-2015). Mundo Agrario, 19(42), e096. https://doi.org/10.24215/15155994e096

Recibido: 09 mayo 2018 - Aceptado: 14 septiembre 2018 - Publicado: 07 diciembre 2018 (c) (1) (2)(2) Esta obra está bajo licencia Creative Commons Atribución-NoComercial-CompartirIgual 4.0 Internacional
http://creativecommons.org/licenses/by-nc-sa/4.0/deed.es_AR 


\title{
Políticas agrarias, Seguridad Alimentaria y Nutricional y Soberanía Alimentaria: luces y sombras del caso cubano $(1990-2015)^{1}$
}

\author{
Agricultural policies, Nutritional and Food Security and Food Sovereignty: lights and shadows of the Cuban case \\ (1900-2015)
}

Elisa Botella Rodriguez

Departamento de Economia e Historia Económica. Instituto

de Iberoamérica, Universidad de Salamanca, España

ebotella@usal.es

\section{RESUMEN:}

Partiendo del concepto multidimensional de Seguridad Alimentaria y Nutricional (SAN) establecido por la FAO, este artículo analiza las políticas agrarias implementadas en Cuba, con especial relevancia desde la etapa liderada por Raúl Castro, y su impacto en la disponibilidad, acceso, estabilidad y utilización de los alimentos, utilizando la base de datos de la FAO (Food Security Indicators) para el período 1990-2015. Para completar el análisis y entender la relación entre determinadas dimensiones de la SAN, en particular la estabilidad y acceso, el estudio propone una quinta dimensión de autonomía alimentaria. Esta quinta dimensión además relaciona las SAN y la soberanía alimentaria en las condiciones especiales de Cuba.

Palabras Clave: Cuba, Políticas agrarias, Seguridad alimentaria y nutricional, Soberanía alimentaria, Agricultura familiar.

\section{Abstract:}

Considering FAO's definition of multidimensional Food and Nutritional Security (FNS), this paper discusses agricultural policies implemented in Cuba during the Special Period. The article particularly focuses on those policies implemented by Raul Castro's Administration and their impact on the different dimensions of FNS: accessibility, availability, utilisation and stability (Food Security indicators) from 1990 to 2015. The paper also proposes a fifth dimension of FNS based on autonomy and food import substitution. This dimension is an attempt to relate food sovereignty and food security in the particular circumstances of Cuba.

KEYWORDS: Cuba, Agricultural policies, Food and nutritional security, Food sovereignty and family farming.

\section{DePENDENCIA DE IMPortaciones de ALimentos. Un PRoblema endémico de Cuba}

La Revolución cubana estableció la alimentación como un derecho humano fundamental a través de la implementación de un sistema de racionamiento y otros subsidios adicionales. Para cumplir precisamente ese compromiso revolucionario con la alimentación, se pusieron en marcha diferentes intentos de promoción de la producción nacional (como el sector lácteo) de alimentos con el objetivo de aumentar su oferta doméstica.

Sin embargo, al igual que la mayoría de países pequeños en desarrollo (especialmente en el Caribe), Cuba importaba históricamente una gran cantidad de los alimentos necesarios para su población (Nova, 2001, 2006). Las ratios de dependencia de las importaciones ya eran elevadas antes de la Revolución, que alcanzaban el $31 \%$ en 1954. Con el paso del tiempo, Cuba se convirtió de manera progresiva en un país cada vez más dependiente de las fuentes extranjeras y subsidiadas de alimentos (Nova, 1993). Rosset y Benjamin (1994, p. 4) señalan que la dependencia de las importaciones de alimentos "ha demostrado ser el Talón de Aquiles de la Revolución”. En 1980 Cuba importaba el 70,7 \% de los alimentos disponibles para la población. Este número fue disminuyendo modestamente hasta 1989, momento en el que las importaciones de alimentos correspondían al 60,2 \% de la comida disponible en la isla (ver Tabla 1) (Álvarez, 2004; FAO, 1997; Nova, $1993)^{2}$. 
Tabla 1: Relación entre las importaciones de alimentos y los alimentos disponibles para el consumo doméstico, 1980-1997 (1000 toneladas métricas)

\begin{tabular}{|c|c|c|c|}
\hline Año & $\begin{array}{c}\text { Alimentos } \\
\text { disponibles para el } \\
\text { consumo }\end{array}$ & Importaciones & $\begin{array}{c}\text { Ratio de } \\
\text { dependencia de las } \\
\text { importaciones *\%) }\end{array}$ \\
\hline & & & \\
1980 & 5.554 & 3.928 & 70,7 \\
1989 & 5.968 & 3.596 & 60,2 \\
1997 & 5.172 & 2.172 & 42,0 \\
& & & \\
\hline
\end{tabular}

Fuente: Datos reportados por la FAO hasta 1997. A partir de 1997 la FAO presenta ratios por grupos de productos y desde 2011 una base multidimensional de Food Security Indicators. * Importaciones dividas entre los alimentos disponibles para el consumo.

El colapso de la Unión Soviética en 1989 forzó a la isla a enfrentar un complicado dilema: ¿cómo sostener a la población cubana sin las importaciones estratégicas de los países del Consejo de Ayuda Mutua Económica $(\mathrm{CAME})^{3}$ ? A pesar del compromiso nacional de seguridad alimentaria, en 1993 Cuba se enfrentó a una crisis alimentaria que redujo de manera dramática la ingesta kilocalórica por debajo de las $2400 \mathrm{kcal} /$ persona/día (Álvarez, 2004; FAO, 2009; Ferriol, 1996, 1998) ${ }^{4}$. En el peor momento del Período Especial el consumo diario de alimentos bajó hasta $1863 \mathrm{kcal} /$ persona/día mientras el consumo de proteínas y grasas cayó a 46 gramos y 26 gramos respectivamente, ambos muy por debajo de los requerimientos necesarios recomendados por la FAO (Ferriol, 1998) ${ }^{5}$. Una vez que Cuba perdió sus favorables términos de intercambio y las elevadas importaciones subsidiadas de alimentos garantizadas por los países del CAME, las ratios de importaciones de alimentos cayeron hasta el $42 \%$ en 1997 (Alvarez, 2004; FAO, 1997).

Las zonas urbanas y suburbanas enfrentaron mayores deficiencias alimentarias. Dada la dependencia histórica de la ciudad de La Habana de las importaciones de alimentos y las provisiones de las zonas rurales, la capital se vio particularmente afectada (Murphy, 1998, 1999). La crisis condujo a una búsqueda generalizada de alternativas para alimentar a la población. Los pequeños productores se situaron a la cabeza de dicho proceso.

A pesar de las complicadas condiciones de principios de los años 90 del siglo pasado, en 1996 la disponibilidad de energía (2335 kcal/persona/día) ya era un 15,8 \% mayor que en 1993. Durante el bienio 1995-97 la ingesta de grasas en los balances energéticos aumentó un 19,6\%. En 1999 la disponibilidad de hortalizas per cápita alcanzó sus mayores rendimientos en 30 años (223,8 g por persona al día), 2,2 veces más elevada que los niveles de 1993 (102,7 g/persona/día) (ONE, 2000; Rodríguez-Ojea et al., 2001). Siguiendo esta tendencia, el consumo de alimentos pasó de $2.440 \mathrm{kcal} /$ persona/día en $1995-97$ a 3.280 en 2003-05 y el número de personas desnutridas, según el indicador World Food Summit (WFS), cayó del 1,5 \% al 0,1 $\%$ durante el mismo período. Más aún, en 2003-05 la prevalencia de la desnutrición en Cuba era menor del $5 \%$, muy por debajo de los niveles medios para América Latina y el Caribe (8\% y $23 \%$ respectivamente) (FAO, 2009).

Estos avances son particularmente notorios si se tienen en cuenta las precarias circunstancias de la agricultura cubana durante el Período Especial, la falta de importaciones estratégicas de alimentos de la antigua Unión Soviética y la necesidad de ser reemplazadas por producción local para alimentar a la población. En este contexto, cabe preguntarse: ¿cuál ha sido la evolución reciente de la seguridad alimentaria en Cuba?, ¿qué papel pudieron jugar las políticas agrarias y, dentro de éstas, qué impacto tuvieron aquellas destinadas a la sustitución de importaciones y la producción familiar?

Para poder responder a estas preguntas es necesario definir la seguridad alimentaria y sus dimensiones, así como la soberanía alimentaria, para aplicarla al caso cubano. Las secciones subsiguientes establecen el marco 
teórico de seguridad y soberanía alimentaria para aproximar ambos conceptos y analizar sus dimensiones en el caso de Cuba.

\section{SEGURIDAD ALIMENTARIA Y SOBERANÍA ALIMENTARIA: MARCO TEÓRICO}

Existe seguridad alimentaria cuando todas las personas tienen, en todo momento, acceso físico y económico a suficientes alimentos, inocuos y nutritivos para satisfacer sus necesidades alimenticias y sus preferencias en cuanto a los alimentos, a fin de llevar una vida activa y sana (FAO, 2001; Gordillo y Méndez, 2013, p. 4).

La noción de seguridad alimentaria ha ido evolucionando a lo largo del tiempo. Surgió en la década de 1970, basada en la producción y disponibilidad alimentaria a nivel global y nacional. En ese momento se relacionaba fundamentalmente con la utilización de stocks y la existencia de provisiones para hacer frente a las emergencias alimentarias (FAO, 1996, 2006; PESA-FAO, 2011). En la década de 1980, el concepto de seguridad alimentaria evolucionó incorporando la idea de acceso, tanto económico como físico. Esta nueva definición se enfocaba hacia la autosuficiencia, y señalaba que un país tenía seguridad alimentaria cuando podía producir todo lo que consumía. Se basaba prácticamente en una visión autárquica o de "desarrollo mirando hacia dentro". De esta manera y con un modelo centrado en el mercado interno, si un país consumía todo lo que producía se estaba protegiendo de las fluctuaciones de precios en el mercado internacional y la escasez ante los shocks externos, como condiciones climáticas adversas o crisis económicas (FAO, 1996, 2006).

En la década de 1990, con la liberalización de los mercados y la promoción de los tratados de libre comercio, la seguridad alimentaria se dejó de entender como un problema exclusivo de disponibilidad de alimentos. Puede haber abundancia de alimentos y, sin embargo, limitaciones de acceso a los mismos debido a problemas estructurales que impiden el acceso a recursos básicos como la tierra, el agua o el mercado. En este sentido, el concepto de seguridad alimentaria se centró en las limitaciones de acceso de los hogares y adquirió una visión más descentralizada. Aunque un país produzca una elevada cantidad de alimentos, su población puede padecer problemas de seguridad alimentaria y nutricional. El doble estándar del comercio internacional (proteccionismo en los países desarrollados frente a la liberalización indiscriminada en los países en desarrollo) unido a las políticas internas de desmantelamiento de granos básicos y apoyo a los productos no tradicionales de exportación son algunas de las razones de estos problemas de acceso y disponibilidad en América Latina.

A partir de este último enfoque, se llegó al concepto actual que incorpora la inocuidad y las preferencias culturales, reafirmando la seguridad alimentaria como un derecho humano basado en el derecho a la alimentación. El resultado ha sido por tanto el establecimiento de un concepto amplio y multidimensional basado en 4 pilares: la disponibilidad, el acceso, la utilización biológica de los alimentos, así como la estabilidad de los tres elementos anteriores en el largo plazo (ver Tabla 2). El cumplimiento de la seguridad alimentaria solo se logra al considerar simultáneamente las cuatro dimensiones.

Por otro lado, la soberanía alimentaria surge como un concepto político desarrollado por la Vía Campesina y llevado al debate público durante la Cumbre Mundial de la Alimentación en $1996^{6}$. La importancia de la soberanía alimentaria se basa en revitalizar la agricultura familiar y campesina, así como su contribución a la producción nacional de alimentos con tecnologías poco dependientes de insumos externos, maquinaria y tecnología importada, la sustitución de alimentos importados y el acceso mejorado a la tierra y los mercados domésticos. Además, trata de aumentar las oportunidades de ingresos y empleo de los pequeños productores a través deladescentralización, los programas de reforma agraria redistributiva y la creación de espacios locales donde los agricultores familiares venden su producción y compran otros bienes básicos en negocios locales (Rosset, 2011; Vía Campesina, 2002) ${ }^{7}$ 
Tabla 2: Dimensiones de la SAN

\begin{tabular}{|l|l|}
\hline $\begin{array}{l}\text { DISPONIBILIDAD } \\
\text { FíSICA de los } \\
\text { alimentos }\end{array}$ & $\begin{array}{l}\text { Parte correspondiente a la oferta, en función del nivel de } \\
\text { producción de alimentos, los niveles de las existencias y el } \\
\text { comercio neto. }\end{array}$ \\
\hline $\begin{array}{l}\text { ACCESO } \\
\text { económico y físico a } \\
\text { los alimentos }\end{array}$ & $\begin{array}{l}\text { Una oferta adecuada de alimentos a nivel nacional o internacional } \\
\text { por sí misma no garantiza la seguridad alimentaria a nivel de los } \\
\text { hogares. La insuficiencia en el acceso a los incluye ingresos y } \\
\text { gastos. }\end{array}$ \\
\hline $\begin{array}{l}\text { UTILIZACIÓN de los la que el cuerpo aprovecha los diversos nutrientes } \\
\text { aresentes en los alimentos. La ingesta de energía y nutrientes } \\
\text { alimentos }\end{array}$ & $\begin{array}{l}\text { alicientes es el resultado de buenas prácticas de salud y } \\
\text { diversidad de la dieta y la buena distribución de los alimentos } \\
\text { dentro de los hogares }\end{array}$ \\
\hline $\begin{array}{l}\text { ESTABILIDAD en el } \\
\text { tiempo de las tres } \\
\text { dimensiones } \\
\text { anteriores }\end{array}$ & $\begin{array}{l}\text { Asegurar el debido acceso a los alimentos de manera periódica. } \\
\text { Las condiciones climáticas adversas (la sequía, las inundaciones), } \\
\text { la inestabilidad política, o los factores económicos (el desempleo, } \\
\text { los aumentos de los precios de los alimentos) pueden afectar a la } \\
\text { seguridad alimentaria de las personas. }\end{array}$ \\
\hline
\end{tabular}

Fuente: FAO, 2006, p. 1

El problema es que la mayor parte de las estrategias que se aproximan a la soberanía alimentaria permanecen como experiencias locales o forzadas por shocks externos o crisis, como el Período Especial en Cuba o la crisis alimentaria global. Precisamente uno de los problemas fundamentales de la soberanía alimentaria es la falta de análisis en profundidad de la dimensión internacional del comercio agrario. ONGs como la Vía Campesina no están en contra de los intercambios, sino más bien se oponen a la prioridad de los modelos basados en las exportaciones. Señalan la importancia de dotar a estos intercambios de un nuevo marco de ayudas públicas y acuerdos internacionales en el que se priorice la producción local y regional frente a la exportación (por ejemplo el comercio justo) (IFAD, 2006; Madeley, 2002; Third World Network \& IFAD, 2006; Vía Campesina, 2002)

Otro de los problemas que presenta la soberanía alimentaria es su medición. Se trata de un concepto político con un objetivo multidimensional que incluye diversos aspectos cualitativos y cuantitativos. OrtegaCerdá y Rivera-Ferre (2010), tras un análisis discursivo del concepto de Soberanía Alimentaria, establecieron cinco categorías de indicadores y sus respectivas subcategorías. Para la categoría 1 de acceso a los recursos existen algunos indicadores para muchas de las subcategorías (acceso a la tierra, acceso a los animales, riego, agua, fertilizantes, etc.). Prácticamente no hay ninguna información del acceso al crédito y otros servicios financieros para el pequeño y mediano agricultor, la distribución de los recursos forestales y marinos y el acceso a las semillas. En las categorías de modelos de producción (categoría 2) y transformación $y$ comercialización (categoría 3) hay una falta de información sistemática y precisa en aspectos esenciales para la soberanía alimentaria. Los datos son limitados para el nivel de concentración empresarial en la cadena alimentaria, la priorización de la comercialización en los mercados locales y regionales, la producción agroecológica y la dependencia energética del actual sistema agrícola y la sostenibilidad de las capturas pesqueras. En la categoría 4 de seguridad y consumo alimentario existe bastante información disponible gracias a las Estadísticas de Seguridad Alimentaria de la FAO. Es, sin embargo, prácticamente inexistente la información sobre la adecuación de la alimentación a las características culturales donde se consumen los alimentos. Por último, en la categoría 5, políticas agrarias, se detectaron insuficiencias claras en el ámbito de la participación de los agricultores en la toma de decisiones, la capacidad de organización en el ámbito agrario 
y algunos aspectos vinculados a los derechos humanos y las migraciones campesinas, todos ellos elementos primordiales para la soberanía alimentaria.

En definitiva, ambos conceptos presentan una perspectiva multidimensional. Sin embargo, la SAN es un concepto neutro que no prejuzga la concentración y diseño del mercado internacional, pero sí trata de promover mejores prácticas agrícolas que puedan coexistir para alimentar a la población. Aunque el concepto de soberanía alimentaria no es opuesto, tampoco es alternativo a la seguridad alimentaria. Si se tienen en cuenta las asimetrías del comercio internacional y las negociaciones comerciales, la soberanía alimentaria como concepto político van más allá de la definición de la SAN dentro del estado moderno y su capacidad para definir políticas alimentarias. Sin embargo, su otro componente, basado en la recuperación de la capacidad más sostenible de los pequeños productores de alimentos destinados al consumo nacional, está mucho más cerca de la SAN en lo que al diseño de políticas públicas se refiere (ver Tabla 3 donde se relacionan definiciones, diferencias y similitudes entre ambos conceptos).

Este artículo se centra en las categorías 4 (Food security indicators) y 5 (políticas agrarias implementadas para analizar la evolución de la seguridad alimentaria en Cuba). Para la categoría 4, el único indicador disponible que nos permitirá una aproximación completa entre la SAN y la soberanía alimentaria son los datos de seguridad alimentaria elaborados por la FAO desde 2011. Una verdadera base de datos multidimensional que se emplea para entender el grado de cumplimiento de las cuatro dimensiones de la SAN en Cuba en la sección 4.

Tabla 3: Conceptos de la SAN y de la Soberanía Alimentaria

\begin{tabular}{|c|c|}
\hline $\begin{array}{l}\text { Seguridad alimentaria y nutricional (SAN) } \\
\text { (FAO) }\end{array}$ & $\begin{array}{c}\text { Soberanía alimentaria } \\
\text { según definición de Vía Campesina }\end{array}$ \\
\hline $\begin{array}{l}\text { Definición multidimensional, SAN } \\
\text { Entorno político, social y económico } \\
\text { pacífico, estable y propicio } \\
\text { Democracia, promoción y protección de } \\
\text { todos los derechos humanos y libertades } \\
\text { fundamentales } \\
\text { Participación plena y equitativa de } \\
\text { hombres y mujeres }\end{array}$ & $\begin{array}{l}\text { También multidimensional, SA } \\
\text { Se amplió el concepto de SA hacia la } \\
\text { soberanía alimentaria con } 6 \text { pilares: } \\
\text { 1. Alimento para los pueblos } \\
\text { 2. Proveedores de alimentos } \\
\text { 3. Localiza los sistemas alimentarios } \\
\text { 4. Control a nivel local } \\
\text { 5. Conocimiento y habilidades } \\
\text { tradicionales } \\
\text { 6. Compatible con la naturaleza } \\
\text { Mayor énfasis en los Países Menos } \\
\text { Desarrollados (PMD) }\end{array}$ \\
\hline $\begin{array}{l}\text { Concepto neutro: no político. } \\
\text { No prejuzga la concentración de poder } \\
\text { económico. } \\
\text { Organismo intergubernamental y multilateral: no } \\
\text { adopta una posición única respecto a las } \\
\text { formas de producir alimentos. } \\
\text { A poyo a la agricultura familiar en la } \\
\text { producción nacional de alimentos }\end{array}$ & $\begin{array}{l}\text { Concepto político: se enfoca en las } \\
\text { asimetrías del mercado internacional. } \\
\text { Papel equilibrador del Estado } \\
\text { democrático. } \\
\text { Producción de alimentos basada en la } \\
\text { agricultura familiar sostenible. }\end{array}$ \\
\hline
\end{tabular}




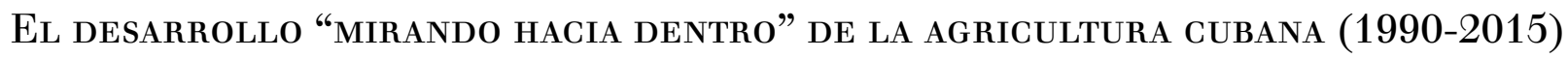

Con el colapso de la Unión Soviética a principios de la década de 1990 el intercambio comercial de Cuba cayó un $75 \%$ y las importaciones un $50 \%$ de 1990 a 1993. Al mismo tiempo, el PIB se contrajo un $30 \%$, la inversión doméstica neta disminuyó un 86 \% y el déficit fiscal se incrementó hasta un 158 \% (Canler, 2000; ONE, 1996).

En 1993 la crisis alimentaria obligó a toda la isla a buscar soluciones que guiaran la nueva agenda económica y agrícola del país. El gobierno cubano declaró el Período Especial en tiempos de Paz. Un intento de diversificar la economía y atraer inversión extranjera (y por tanto las divisas requeridas) a diferentes sectores de la economía (ej., la apertura del turismo a través de empresas mixtas) (Álvarez, 2004; Nova, 2006).

En este contexto, Cuba se vio obligada a buscar soluciones internas para alimentar a su población y producir sin los insumos y petróleo importados de los países socialistas. Un número importante de pequeños productores, alentados por diferentes grupos de investigadores y académicos (y sus pesquisas previas en tecnología agraria alternativa desde principios de la década de 1980), impulsaron el desarrollo de en un modelo de agricultura "mirando hacia dentro" basado en dos pilares fundamentales: la sustitución de insumos químicos importados por alternativas locales que presentaban un coste mucho menor, y la vuelta a la tracción animal (Rosset y Benjamin, 1994; Wright, 2005) ${ }^{8}$.

El estado también impulsó cambios en la estructura de la tierra hacia el cooperativismo y la agricultura familiar. Una de las principales medidas adoptadas para estimular la producción interna de alimentos fue el Decreto No 142 que transformó en a partir de 1993 a las antiguas granjas estatales en nuevas cooperativas de producción agrícola denominadas Unidades Básicas de Producción Cooperativa (UBPC). Este decreto también se basó en la entrega de pequeñas parcelas en usufructo para el cultivo de determinados productos (como tabaco) (Martín, 2002). Estas nuevas cooperativas (a pesar de tener problemas de endeudamiento y ociosidad en determinados sectores), junto con una serie de medidas adicionales de liberalización del mercado interno de alimentos (por ejemplo la creación de mercados de libre oferta y demanda en 1994), abrieron espacios para los pequeños productores e incrementaron su capacidad de producir alimentos destinados al consumo nacional a partir de la década de 1990 (Botella-Rodríguez, 2012; 2018).

Como resultado, la estructura de la tierra en Cuba experimentó grandes transformaciones. Mientras que el sector estatal disminuyó de un $75 \%$ en 1992 al 23,2 \% en 2008, el sector no estatal (formado por las UBPC, Cooperativas de Producción agropecuaria, CPA y Cooperativas de Crédito y Servicios, CCS) aumentó un $50 \%$ durante el mismo período (ONE, 2007). En particular, las UBPC agrupaban el 39,8 \% del total de la estructura de la tierra en Cuba en 2008. Las CPA aumentaron ligeramente del $10 \%$ en 1992 al 10,2\% en 2008, las formas individuales de tenencia como las CCS y otras tierras en usufructo casi se duplicaron durante el mismo período. De 1992 al 2008, el cambio más importante experimentado en la tenencia de la tierra no fue solo la creación de las UBPC, sino la expansión gradual de la tierra en manos de los pequeños productores privados (CCS y usufructuarios). Este fue precisamente el pilar de las leyes de reforma agraria implementadas en la era liderada por Raúl Castro a partir de 2008 y hasta 2018.

A partir de 2007, el gobierno cubano puso en práctica una serie de transformaciones destinadas a aumentar la autosuficiencia alimentaria del país y reducir la dependencia de las importaciones. La entrega de tierras en usufructo, aprobada por el Decreto 259 en 2008, profundizó el proceso de descentralización y promoción de la agricultura campesina destinada a la producción de alimentos iniciada en 1993. Más de 170.000 campesinos fueron beneficiados por dicho decreto-ley en todo el país (MINAGRI, 2011). El programa de agricultura suburbana, implementado a partir de 2009-2010 para mejorar el acceso a la alimentación en las zonas rurales, representa otro ejemplo de continuidad en el proceso de descentralización de la tierra y promoción de la producción interna de alimentos durante la etapa liderada por Raúl Castro (2008-2018).

Desde 2011, Cuba está inmersa en un importante proceso de transformación económica, política y social identificado como la "actualización del modelo económico y social". Dicha transformación ha quedado 
recogida en los Lineamientos de la Política Económica y Social del Partido y la Revolución, aprobados en el VI Congreso del Partido Comunista de Cuba (PCC), en abril del 2011. Los Lineamientos constituyen una reforma profunda con objetivos de corto y largo plazo. Entre sus objetivos de corto plazo destacan el control del déficit de la balanza de pagos, la generación de ingresos externos y la sustitución de importaciones. Dentro de los objetivos de largo plazo sobresalen el desarrollo sostenible basado en la autosuficiencia alimentaria y energética, el uso eficiente del potencial humano, la competitividad de las producciones tradicionales y las nuevas producciones de bienes y servicios de alto valor agregado (PCC, 2011).

Precisamente las transformaciones más profundas se han iniciado en el sector agropecuario, un sector económicamente decisivo y estratégico para la sustitución progresiva de alimentos importados. De las 313 directrices contenidas en los Lineamientos, un total de 38 está directamente dedicado a la Política Agroindustrial, mientras que otras 138 directrices de diferentes capítulos se relacionan con el sector. En este sentido, el Decreto-Ley No 259 fue modificado por el No 300 del 2012, con el objetivo de poner en explotación bajo un régimen de usufructo gratuito un volumen de tierras improductivas que llegó, en una primera aproximación, al 18,6 \% del área agrícola de Cuba. Este decreto-ley trata de ampliar la cantidad de tierras disponibles para las personas que poseían relaciones de trabajo con las CPA y CCS. Esta medida ha sido a su vez acompañada de una política de crédito y fiscal favorable, que ha propiciado el asentamiento de nuevos productores en las zonas rurales con el objetivo de impulsar la producción de alimentos.

Se entregaron hasta 2015 más de 1.700 .000 ha de tierras ociosas en usufructo a más de 200.000 personas, tanto por el ya derogado Decreto-Ley 259 como por su sucesor, el Decreto-Ley 282 de 2011 y el DecretoLey 300 de 2012 (Nova, 2013). La Tabla 4 muestra el importante aumento de las CCS y los usufructuarios y las estimaciones de Nova (2013) durante el período 2011-2018 (que incluye a los nuevos usufructuarios).

A pesar de la continuidad en el proceso de descentralización y reestructuración del sector estatal agropecuario, Nova y González (2015) señalan tres problemas fundamentales y todavía no resueltos que afronta el sector para aumentar su producción y productividad. En primer lugar, la necesidad de definir mejor la propiedad de los usufructuarios; en segundo lugar, el reconocimiento y aceptación del mercado como mecanismo complementario de coordinación económica, y, por último, la ausencia de un enfoque integral para conseguir el ciclo de producción agrícola completo de manera exitosa. En este contexto, se analizan a continuación las cuatro dimensiones de la SAN. Además se propone una quinta dimensión para aproximar los conceptos de SAN y soberanía alimentaria particularmente pertinentes en el caso cubano, al ser considerado como un caso paradigmático de dicho enfoque.

Tabla 4: Estructura de la tierra (porcentaje) (2007-2018)

\begin{tabular}{|l|l|l|l|l|l|l|}
\hline Años & Total & Estatal & No estatal & UBPC & CPA & $\begin{array}{l}\text { CC S } \\
\text { usufructuarios }^{\star \star}\end{array}$ \\
\hline 2007 & 100 & 35.8 & 64.2 & 36.9 & 8,8 & 18,5 \\
\hline $\begin{array}{l}2011- \\
2018^{*}\end{array}$ & 100 & 17.0 & 83.0 & 23.0 & 9,0 & 51,0 \\
\hline
\end{tabular}

Fuente: Elaboración propia basada en Nova 2013. ${ }^{*}$ Estimado por Nova, 2013. ${ }^{* *}$ Comprende a los beneficiados por los Decretos Leyes 259,282 y 300.

\section{Evaluación de la SAN en Cuba (1990-2014)}

En 2016 se estimaba que para alcanzar un crecimiento del $1 \%$ en el PIB Cuba necesita un aumento en las importaciones de entre $2 \%$ y 3 \% (Rodríguez, 2016). Entre dichas importaciones, las de alimentos pasaron de 2.200 millones de dólares en 2008 a 1965 millones de dólares en 2015, cifra un 4,5 \% por debajo de la del año 2014 (Chan y Freyre, 2012; Economist Intelligence Unit, 2015). Aunque no aumentó la cantidad de alimentos importados, sí lo hizo el coste en divisas de las importaciones, especialmente en 2007-2008 
con la crisis alimentaria global y el encarecimiento de los costes de transporte y los precios de los productos básicos. Este apartado analiza el impacto de las políticas implementadas, especialmente aquellas puestas en marcha durante a la etapa liderada por Raúl Castro (2008-2018) y descritas anteriormente en la SAN de Cuba. Considera las cuatro dimensiones de la SAN para analizar el caso cubano con especial interés en el binomio disponibilidad-estabilidad. El artículo también propone la inclusión de quinta dimensión denominada autonomía que articula de manera más coherente las 4 dimensiones de la SAN en Cuba. Esta dimensión propuesta también permite una mejor conexión entre la dimensión macroeconómica de los indicadores de la SAN en Cuba y la dimensión micro (los pequeños productores y su creciente contribución a la producción nacional de alimentos) de la misma en la isla.

\section{Dimensión 1: disponibilidad}

Para medir la disponibilidad de alimentos en Cuba se analizan dos indicadores fundamentales: la suficiencia del suministro de energía necesaria promedio y el valor medio de la producción de alimentos. El indicador de suficiencia del suministro de energía alimentaria promedio expresa la oferta de energía disponible como porcentaje de la energía requerida para la dieta promedio ${ }^{9}$. Como muestra el Gráfico 1, la suficiencia del suministro de energía necesaria promedio para Cuba pasó del $113 \%$ en 1990-92 al $143 \%$ en 2014-16. Este indicador de estabilidad está por encima del promedio de los países en desarrollo (120\%), América Latina (129\%) y el Caribe (115\%).

\section{Gráfico 1: Suficiencia del suministro de energía media necesaria \%}

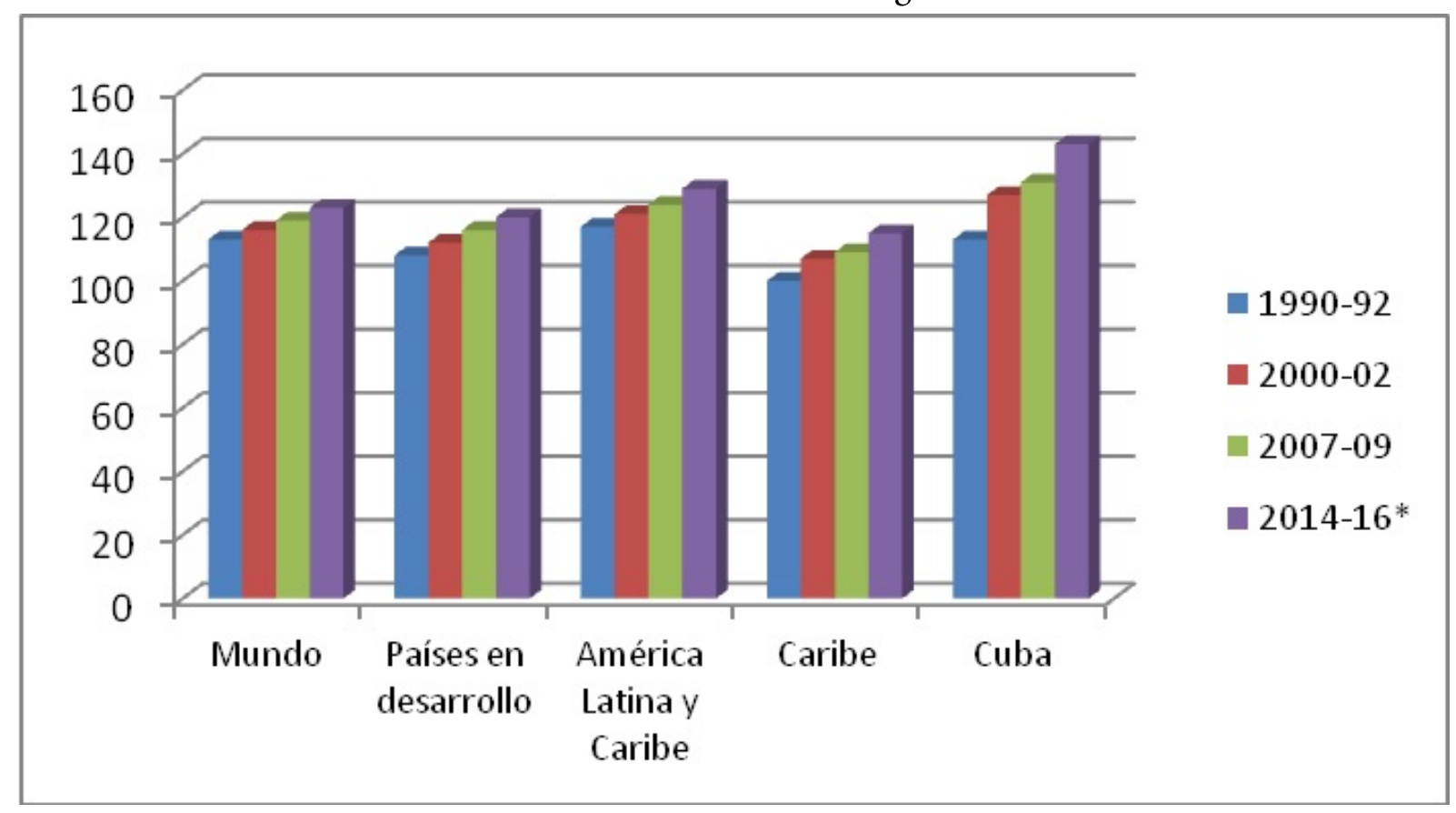

Fuente: Elaboración propia a partir de FAO, 2016. *Estimaciones de la FAO para 2014-2016.

El valor medio de la producción de alimentos (en dólares internacionales constantes de 2004-2006), estimado por la FAO en términos per cápita, proporciona una medida comparable entre países del tamaño económico relativo del sector de producción de alimentos en un país (FAO, 2016). Para Cuba, esta medida pasó de 369 dólares en 1990-92 a 234, en 2007-09, y 245 en 2011-13. Aunque este indicador de disponibilidad es superior a la media de los países caribeños, que pasó de 225 dólares en 1990-92 a 190 en 2011-13, permanece por debajo del promedio regional (América Latina y el Caribe: ALC) de 469 dólares 
per cápita (ver Gráfico 2). Es decir, Cuba tiene una capacidad más limitada en términos de producción de alimentos que otros países latinoamericanos, especialmente de América del Sur.

Para los otros 3 indicadores de disponibilidad en el período 2009-2011, Cuba presenta mejores resultados que el Caribe. La proporción del suministro de energía alimentaria derivado de cereales, raíces y tubérculos según los últimos datos de la FAO (2016) es del $44 \%$ para Cuba, superior al 40 \% para ALC, y el $42 \%$ para el Caribe. El suministro de proteínas promedio para Cuba era de $83 \mathrm{gr} /$ persona/día, que superaba a ALC (82) y el Caribe (con $66 \mathrm{gr} /$ persona/día) en 2009-2011. Por último, el suministro de proteínas de origen animal promedio para Cuba era de $30 \mathrm{gr} /$ persona/día, frente a los 26 del Caribe, pero inferior al suministro para ALC de $41 \mathrm{gr} /$ persona/día para ese mismo período (FAO, 2016). Solo la disponibilidad de proteínas es superior en América Latina con respecto a Cuba.

Gráfico 2: Valor de la producción de alimentos promedio (Dólares constantes de 2004-2006, per cápita)

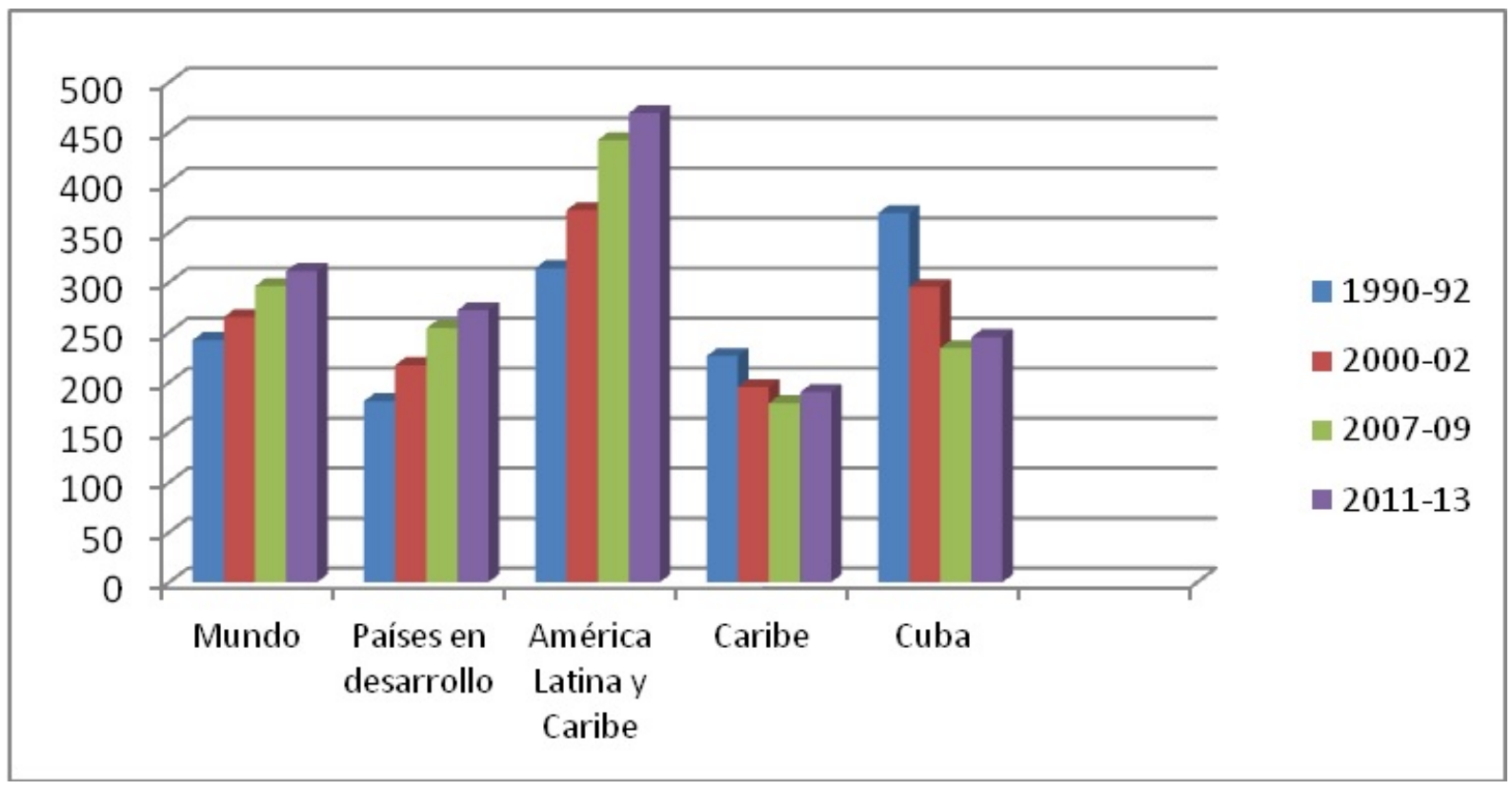

Fuente: Elaboración propia a partir de datos FAO, 2016.

Los datos de la dimensión 1 de la SAN permiten señalar que la disponibilidad no presenta grandes diferencias en Cuba con respecto a los países desarrollados. Los indicadores analizados muestran una elevada disponibilidad especialmente si comparamos Cuba con sus vecinos caribeños.

\section{Dimensión 2: acceso}

La prevalencia de la desnutrición es uno de los principales indicadores del acceso a los alimentos y expresa la probabilidad de que un individuo, seleccionado aleatoriamente entre la población, consuma una cantidad de kilocalorías insuficientes para cubrir los requerimientos energéticos necesarios para una vida activa y saludable (FAO, 2016) ${ }^{10}$. Desde el año 2000 hasta el 2016 la prevalencia de la desnutrición en Cuba ha sido menor del $5 \%$, por debajo de los niveles de América Latina y el Caribe (5,5 \% y 19,8\%, respectivamente) en 2016 (FAO, 2016). A su vez, el déficit alimentario indica cuántas kilocalorías se necesitarían para sacar a la población desnutrida de su estatus, mientras que todo lo demás permanece constante ${ }^{11}$. En Cuba la intensidad del déficit alimentario pasó de $39 \mathrm{kcal} /$ persona/día en 1990 a 122 en 1996-98 durante el Período Especial, y cayó de manera significativa a partir de 2000-02 (27 kcal/persona/día) y hasta 2014-2016 (7 kcal/ 
persona/día). Estos valores se encuentran muy por debajo de la media de América Latina y el Caribe (ver Gráfico 3) (FAO, 2016).

Gráfico 3: Intensidad del déficit alimentario (kcal/persona/día)

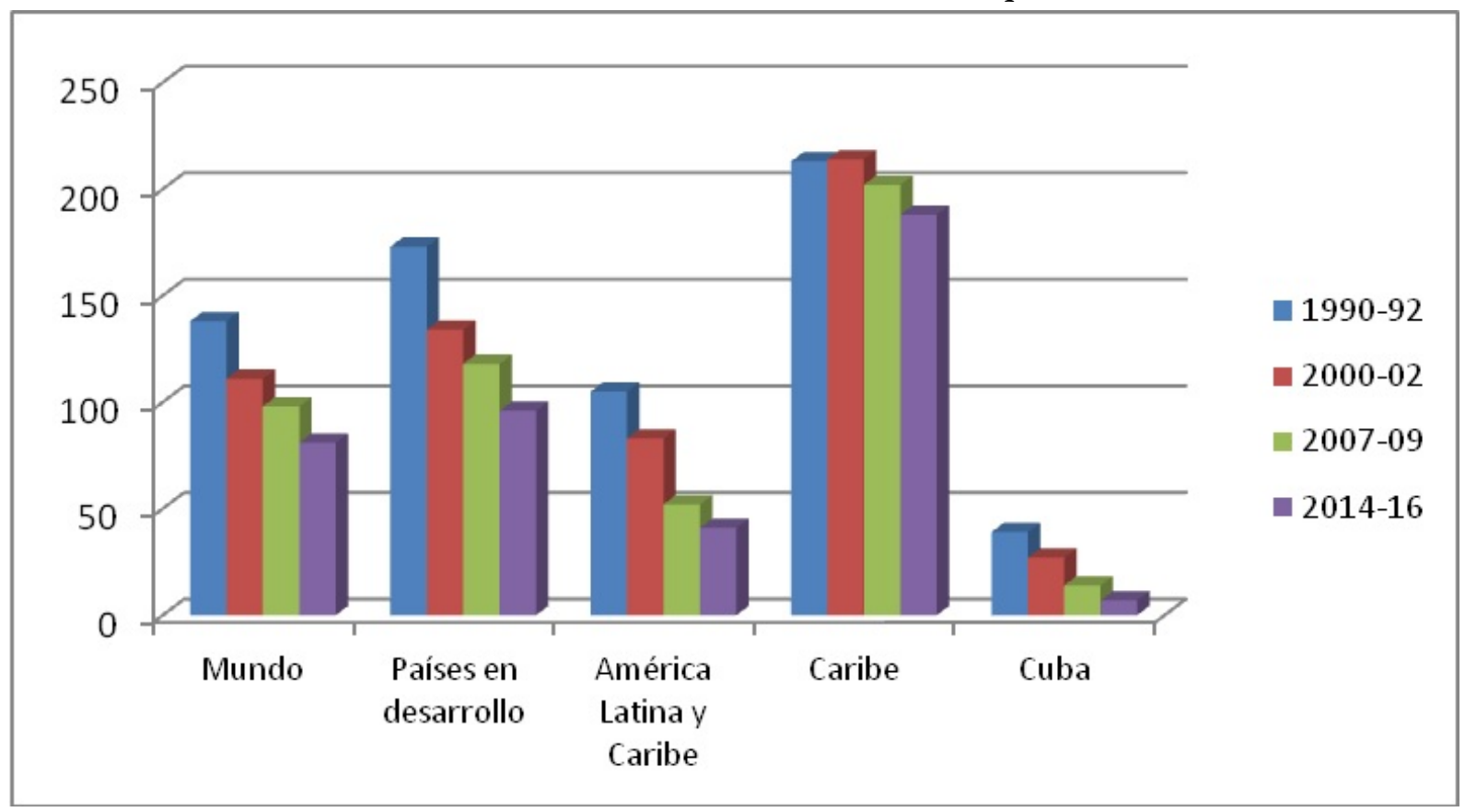

Fuente: Elaboración propia a partir de los datos de FAO, 2016.

Otros indicadores de acceso para Cuba, como el porcentaje de carreteras asfaltadas sobre el total de caminos en 2010 muestran un valor del 81,9\% para Cuba, frente al 21,4\% para ALC. Con respecto a la densidad de líneas ferroviarias, los datos de 2009 indican para Cuba el 4,6\% por $100 \mathrm{~m}^{2}$ de superficie disponible frente al $0,5 \%$ en ALC ese mismo año $(\mathrm{FAO}, 2016)^{12}$. Por último, otra de las variables fundamentales para determinar el acceso a los alimentos es el PIB per cápita (en poder adquisitivo equivalente). En Cuba este era de 19950,30 (US dólares internacionales constantes de 2011) en 2013 frente a 14288,5 en ALC y 14007,1 en el Caribe.

En definitiva, Cuba muestra una situación favorable en términos de acceso a partir de las diferentes variables analizadas para esta dimensión. La seguridad alimentaria en la isla no parece por tanto responder a un problema de acceso a nivel macroeconómico, a pesar de que esta dimensión se haya deteriorado desde el comienzo del Período Especial.

\section{Dimensión 3: utilización}

Para entender la tercera dimensión de la SAN en Cuba se analiza el acceso a los servicios de saneamiento mejorados (entre los indicadores disponibles) para la utilización biológica de los alimentos donde la isla presenta un acceso superior a la media de ALC (ver Tabla 5).

Tabla 5: Acceso a servicios de saneamiento mejorados (\% de la población con acceso)

\begin{tabular}{|c|c|c|c|}
\hline Regiones/subregiones/países & $\mathbf{1 9 9 0}$ & $\mathbf{2 0 0 0}$ & $\mathbf{2 0 1 4}$ \\
\hline Mundo & 54,4 & 58,8 & 65,2 \\
\hline Países en desarrollo & 39,8 & 47,0 & 56,7 \\
\hline América Latina y el Caribe & 67,3 & 74,6 & 83,0 \\
\hline El Caribe & 68,0 & 70,5 & 73,8 \\
\hline Cuba & 81,5 & 86,7 & 93,2 \\
\hline
\end{tabular}


Otros indicadores de utilidad como el porcentaje de niños menores de cinco años que padecen retraso en el crecimiento solo representaban para Cuba el $7 \%$ en el año 2000. El porcentaje de adultos con insuficiencia ponderal o prevalencia de carencias de vitamina A en la población fue de 3,6 \% en el año 2000 (FAO, 2016). Ambos indicadores muestran las buenas condiciones que presenta la SAN al analizar la dimensión de utilización en Cuba. El resto de indicadores de utilización no presentan datos y por tanto no son representativos para Cuba.

\section{Dimensión 4: estabilidad (incluye disponibilidad y acceso)}

Datos actualizados de la FAO (2016) sobre seguridad alimentaria y nutricional, como los valores de las importaciones de alimentos con respecto al total de la mercadería exportada, muestran una caída del $50 \%$ en el período 2003-2005 al $32 \%$ en 2011-2013 (ver Gráfico 4). Este es un indicador de vulnerabilidad y captura la capacidad de las reservas de divisas de un país para pagar las importaciones de alimentos, con implicaciones para la seguridad alimentaria del mismo país, según sus patrones de producción e intercambio (exportaciones e importaciones). Un indicador importante para Cuba si se tiene en cuenta su larga historia de dependencia alimentaria.

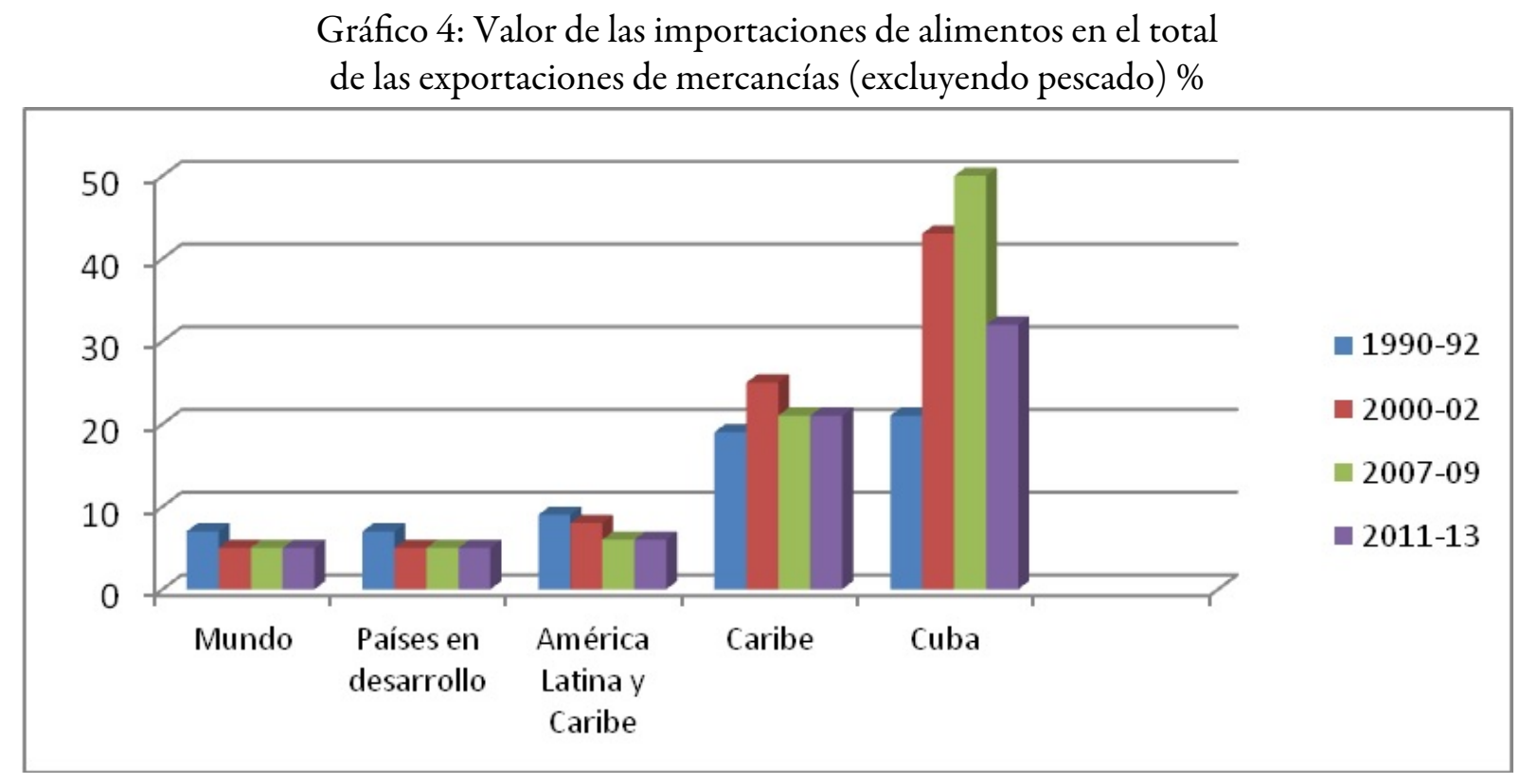

Fuente: Elaboración propia basada en los datos de la FAO, 2016.

Otro de los indicadores de estabilidad empleado es el de la proporción de dependencia de importaciones de cereales que muestra la ratio de la oferta de cereales disponibles que ha sido importada y el porcentaje que proviene de la producción interna de un país ${ }^{13}$. En Cuba este indicador cayó ligeramente en los últimos años: pasó del 77,5 \% en 2005-2007 al 75,5 \% en 2009-2011, aunque se ha mantenido elevado (ver Gráfico 5) (FAO, 2016).

Otro indicador de estabilidad es el porcentaje de tierra arable provista de sistemas de riego. En este caso, para el período 2011-2013, Cuba presentaba el 17,2 \% frente al 19,5\% en el Caribe y el 14,2 \% en ALC en el mismo período. La variabilidad de la producción de alimentos per cápita (en dólares constantes de 2004-2006 per cápita) para el 2013 era de 9,1 en Cuba, frente a 4,5 en el Caribe y 10,1 en ALC en el mismo año, y, por 
último, la volatilidad del suministro de alimentos per cápita en 2001 era de 91 (kcal/persona/día) en Cuba, frente a 10 en ALC y 34 en el Caribe (FAO, 2016).

Gráfico 5: Ratio de dependencia de cereales importados (\%)

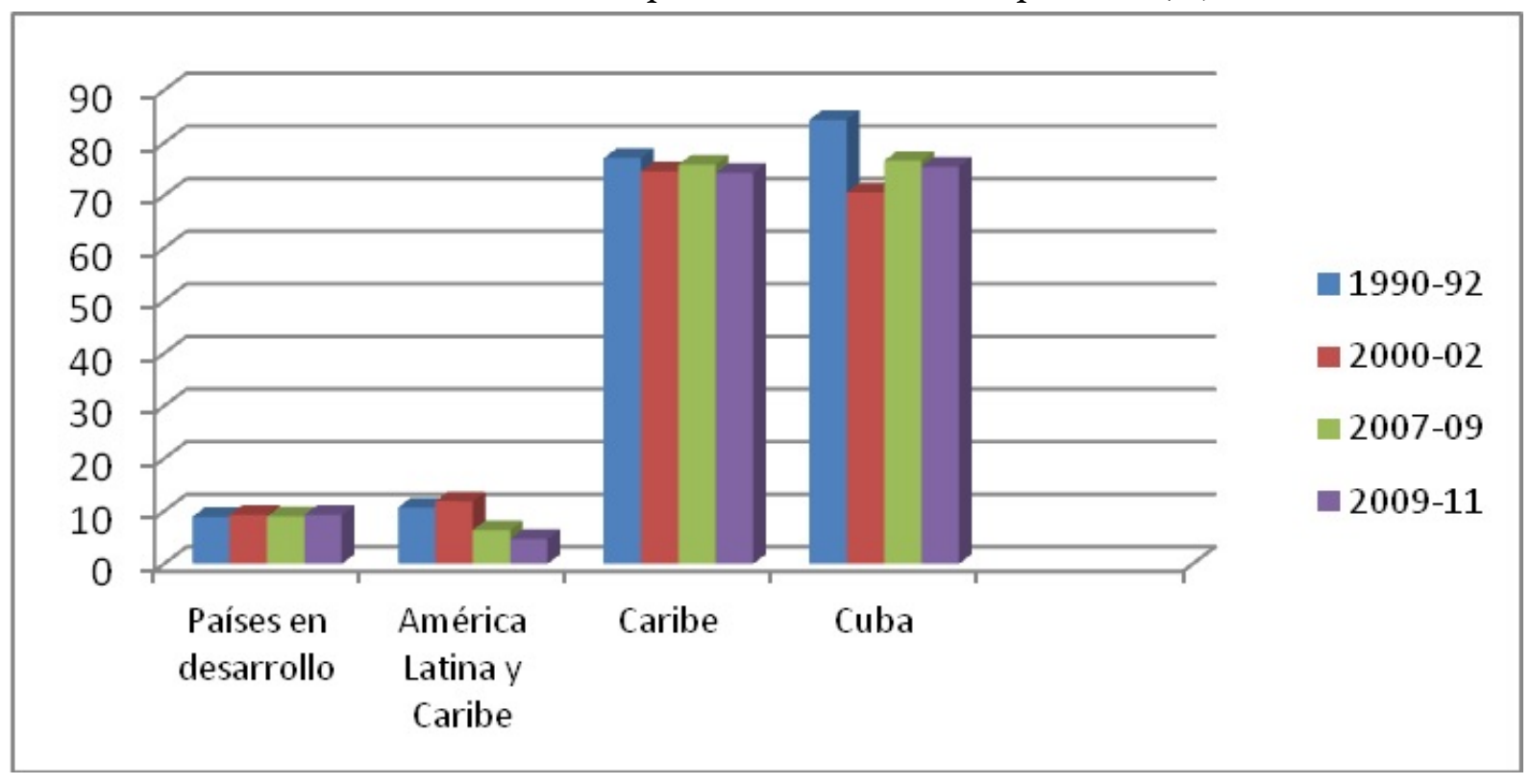

Fuente: Elaboración propia basada en FAO, 2016.

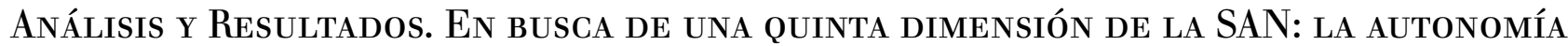 BASADA EN LA RELACIÓN ENTRE DISPONIBILIDAD, ACCESO Y ESTABILIDAD}

El análisis de las cuatro dimensiones de la SAN en Cuba muestra resultados parecidos a los de países desarrollados, principalmente en términos de acceso, disponibilidad y utilización. stos se deben en gran medida a las políticas públicas implementadas en el sector primario. La relación entre disponibilidad y estabilidad sin embargo muestra algunos problemas. La insuficiente producción nacional de alimentos ha sido una dificultad constante en Cuba, que ha hecho al país vulnerable a los shocks externos. La dependencia de elevadas cantidades de divisas para la importación de alimentos, a pesar de que la mayoría de productos podrían producirse nacionalmente bajo condiciones de competitividad (alrededor del $40 \%$ ), hacen a Cuba todavía vulnerable ante esos shocks. Cuba dispone de una base material, aunque descapitalizada en gran medida durante el Período Especial, que puede ser mejorada y utilizada, y un importante capital humano que otros países de la región no presentan (Nova, 2013).

Sin embargo, la dimensión de estabilidad debe relacionarse en Cuba con la autonomía y el progresivo proceso de sustitución de importaciones de productos básicos que se está consiguiendo en la isla desde mediados de la década de 1990. Las mejoras en los niveles nutricionales tras la crisis alimentaria de 1993 no han sido el resultado de un aumento directo y exclusivo de la cantidad de alimentos importados, ya que éstos cayeron hasta el 60,2 \% en 1989 y el $42 \%$ en 1997 (FAO, 1997). En este sentido, un análisis más específico de las ratios de alimentos importados por grupo de productos para el período 1990-92 y 2005-07, basado en los datos de la FAO (2009), nos muestra como los cereales (-6,7\%), las hortalizas (0,66\%), la carne (19,04\%), las leguminosas $(20,6 \%)$ y los aceites vegetales $(21,3 \%)$, claves para cubrir las necesidades alimenticias de la isla, redujeron sus ratios de importación en puntos porcentuales (ver Tabla 6 y Gráfico 6) (FAOSTAT, 2009). 
Tabla 6: Evolución de los ratios de alimentos importados (kg/persona/año) (1990-2007)

\begin{tabular}{|c|c|}
\hline Grupos de productos & Diferencias en puntos porcentuales \\
\hline Cereales - Excluida la cebada & -6.7 \\
\hline Raíces/tubérculos & -1.28 \\
\hline Azúcar y edulcorantes & 14.06 \\
\hline Leguminosas (ej. guisantes, frijoles y lentejas) & -20.6 \\
\hline Oleaginosas & 58.2 \\
\hline Aceites Vegetales & -21.3 \\
\hline Verduras y hortalizas & -0.66 \\
\hline Frutas - Excluida la vid & 0.28 \\
\hline Carne & -19.04 \\
\hline Vísceras & 9.09 \\
\hline Grasas animales & 53.65 \\
\hline Leche - Excluida la mantequilla & 24.2 \\
\hline
\end{tabular}

Fuente: cálculo del autor a partir de FAO, 2009.

Gráfico 6: Ratios de importaciones de alimentos en Cuba (kg/persona/día)

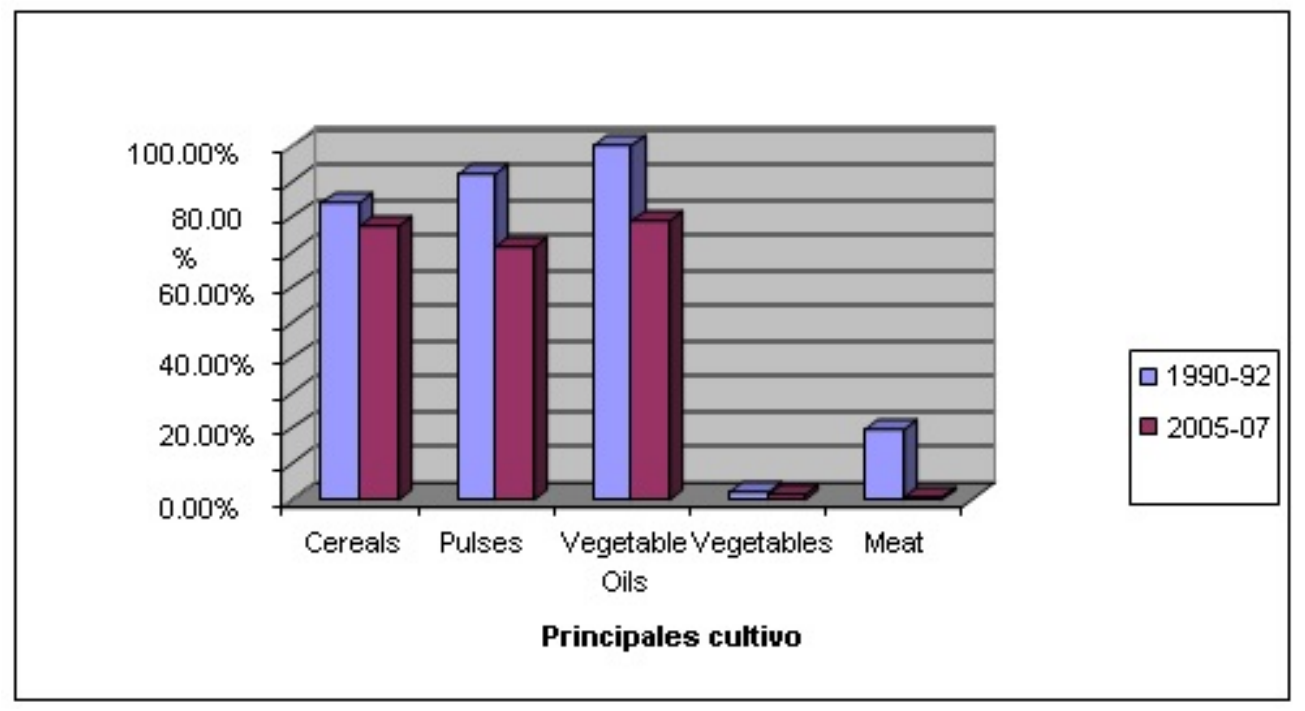

Fuente: elaboración propia basada en FAO country statistics, 2009.

Estos datos ofrecen resultados mixtos si los comparamos con los indicadores de estabilidad que muestran una continuada dependencia de las importaciones de alimentos en Cuba. Sin embargo, las ratios de determinados productos claves en la dieta nacional han caído de manera significativa. En este sentido, el análisis de la contribución y niveles de producción del sector no estatal, en particular, los productores individuales (CCS y usufructuarios) y su participación en la producción nacional de alimentos es clave para entender las posibles reducciones en las importaciones de alimentos de la isla desde 1990 hasta 2015 (ver Tabla 7). Esta variable es particularmente notoria durante la era liderada Raúl Castro y responde a las diferentes medidas de entrega de tierras en usufructo anteriormente explicadas.

En el año 2000, el sector no estatal producía el 77,8 \% del arroz, el 87,1 \% del maíz y el 91,5\% de los frijoles disponibles para el consumo nacional (ONE, 2000). En 2008 los pequeños productores privados producían el $82 \%$ del maíz, el $81 \%$ de los frijoles y el $36 \%$ del arroz disponible para el consumo nacional. De enero a diciembre de 2015 los productores privados producían el 77,9\% de las viandas y hortalizas, el 60,9\% del arroz cáscara húmedo, el 85,6 \% del maíz, el 78,5 \% de los frijoles y el 85,6 \% de los frutales (ONEI, 2016). Se observa, de este modo, una continuada tendencia en aumento de la producción de alimentos básicos para la dieta nacional en manos de los pequeños productores, especialmente CCS y usufructuario. 
TABLA 7

Producción no azucarera del sector no estatal \%

\begin{tabular}{|c|c|c|}
\hline Cultivos & \% Privado del total & \% \\
& $\mathbf{2 0 0 8}$ & $\mathbf{2 0 1 5}$ \\
\hline Raíces y hortalizas & 50,0 & 74,6 \\
Patatas & 6,1 & 6,3 \\
Bananas & 51,1 & 70,7 \\
Vegetale s/hortalizas & 64,1 & 72,1 \\
Tomate & 68,0 & 83,6 \\
Arroz & 36,0 & 64,1 \\
Maíz & 82,0 & 86,1 \\
Alubias/frijoles & 81.0 & 79,6 \\
Cítricos & 15.0 & 29,5 \\
Frutas tropicales & 74.0 & 81,2 \\
\hline
\end{tabular}

diciembre de 2008-2015 (1,000 toneladas)*

${ }^{*}$ Se excluye el azúcar, parcelas y patios. ${ }^{* *}$ Incluye a las CCS y los

pequeños productores individuales. Fuentes: ONEI, 2009, ONEI, 2016

\section{REFLEXIONES FINALES}

La insuficiente producción nacional de alimentos ha sido (y sigue siendo) un problema recurrente durante los últimos cincuenta años en Cuba. A pesar de la severa crisis que atravesó el país en 1993, tras la caída del campo socialista, Cuba exhibe indicadores de acceso, disponibilidad y utilización muy similares a los de países desarrollados gracias, en gran medida, a las políticas públicas hacia el sector primario, entre las que se destaca la progresiva sustitución de alimentos importados desde mediados de la década de 1990.

Sin embargo, la estabilidad de las tres dimensiones de la SAN muestra algunas deficiencias en Cuba. A pesar de que la mayoría de productos podrían producirse nacionalmente en condiciones de competitividad (alrededor del $40 \%$ ), Cuba necesita elevadas cantidades de divisas para la importación de alimentos ${ }^{14}$. Además, enfrenta desafíos persistentes que impiden un aumento mayor de la producción y productividad agraria nacional. La isla presenta un número importante de áreas agrícolas cultivables ociosas (más de 2 millones de ha), requiere una mejor definición de la propiedad de los usufructuarios, y el reconocimiento y aceptación del mercado como mecanismo complementario de coordinación económica. A su vez, el sector agrario cubano carece de un enfoque integral para conseguir el ciclo de producción completo de manera exitosa.

En este contexto, los retos del modelo agrario cubano versan en torno a una pregunta que subyace desde principios del Período Especial: ¿dónde está el equilibrio dentro del binomio (más) mercado (menos) Estado? La producción nacional requiere la consolidación de un mercado de insumos y crédito, la asistencia técnica necesaria, una mayor autonomía que permita a los productores decidir libremente dónde y a quién pueden vender su producción (después de cumplir con la centralizadora Acopio), y la diversificación de las formas de comercialización agraria con una mayor participación de los actores no estatales, especialmente los productores individuales que son los que ostentan un claro potencial productivo en la isla. En este sentido, se debe profundizar en el análisis de los problemas de organización agraria y en las limitaciones que muestra un enfoque de "desarrollo mirando hacia dentro". Los resultados del caso cubano revelan algunas de las tensiones asociadas a propuestas locales (como la soberanía alimentaria, para la que muchos ven en Cuba un caso paradigmático) y su implementación a nivel nacional.

Por último, en un escenario de apertura regional y globalización, Cuba debe reformular sus políticas agroalimentarias a través del fortalecimiento de sus capacidades locales en función de la estabilidad y 
autonomía alimentaria de la isla. El análisis de la seguridad alimentaria multidimensional, así como la inclusión entre sus dimensiones de la autonomía asociada al tipo de políticas agrarias implementadas en otros países de la región (especialmente en el Caribe y Centroamérica), es una de las líneas futuras de investigación (a través de estudios de casos comparativos) que este artículo trata de promover.

\section{REFERENCIAS}

Álvarez, J. (2004). Cuba's agricultural sector. Florida: University Press of Florida.

Botella-Rodríguez, E. (2012). Patterns of agricultural development and small farming. A comparative study of Costa Rica and Cuba in the global era (1990-2008). (PhD thesis), University of London, London, UK.

Botella-Rodríguez, E. (2018). Food Import Dependency in Cuba: Still the 'Achilles' Heel of the Revolution? Bulletin of Latin American Research (forthcoming-in Earlyview). Recuperado de https://doi.org/10.1111/blar.12848

Canler, E. (2000). The Miracle of the Cuban Economy in the 1990s. Cuba in Transition, 11, 64-69.

Chan, M.L y Freyre, E.F. (2012). Unfinished Puzzle, Cuban Agriculture: The challenges, lessons and opportunities. Canada: Food First Books.

Deere, C. D., (Ed). (1992). Toward a Periodization of the Cuban Collectivization Process: Changing Incentives and Peasant Response. Cuban Studies, 22, 115-149.

Economist Intelligence Unit (EIU). (2015). Country Report Cuba December 2015. Recuperado de https://www.eiu. com (fecha de consulta 20 de abril de 2016).

FAO (Food and Agriculture Organization). (2001). El estado mundial de la Agricultura y la Alimentación. Organización de las Naciones Unidas para la Alimentación y la Agricultura. Roma: FAO.

FAO. (1997). Food Security Statistics. Rome: FAO.

FAO. (2009). Food Security Statistics. Rome. Recuperado de http://www.fao.org/economic/ess/food-security-statisti cs/food-security-statistics-by-country/en/ (fecha de consulta 20 de mayo de 2016).

FAO. (2016). Food Security Statistics. FAOSTAT. Rome: FAO. Recuperado de http://www.fao.org/economic/ess/f ood-security-statistics/food-security-statistics-by-country/en/ (fecha de consulta 20 de junio de 2016).

FAO. (junio, 2006). Seguridad alimentaria. Informe de Políticas. No.2. Roma: FAO. Recuperado de http://www.fa o.org

FAO. 1996. Declaración de Roma sobre la Seguridad Alimentaria Mundial. Cumbre Mundial sobre la Alimentación, 13 al 16 de noviembre. Roma: FAO. Recuperado de http://www.fao.org/docrep/003/w3613s/w3613s00.htm.

Ferriol, A. (1996). La seguridad alimentaria en Cuba. Revista Cuba: Investigación Económica, 2 (3), s/p.

Ferriol, A. (septiembre, 1998). Pobreza en condiciones de reforma económica: el reto a la equidad en Cuba. Trabajo presentado en el XXI Congreso de la Latin American Studies Association. LASA, Chicago, Illinois.

Food Secure Canada. (Novemeber, 2012). 7th National Assembly. Food Secure Canada, Alberta. Resumen recuperado de https://foodsecurecanada.org/who-we-are/our-story/past-assemblies/assembly-2012.

Funes, F. (2002). The organic farming movement in Cuba. En Funes, F., García, L. Bourque, M., N. Pérez, N. y P. Rosset, P. Sustainable agriculture and resistance: transforming food production in Cuba (pp.1-26). Oakland: Food First.

Funes-Monzote, F. (2008). Farming like we are here to stay: the mixed farming alternative for Cuba. (PhD thesis). Wageningen University, Wageningen, Netherlands.

Goldschmidt, W. (1978). As You Sow, Three Studies in the Social Consequences of Agribusiness. New York: Allenheld, Osmun.

Gordillo, G. y Méndez, J. (2013) Seguridad y soberania alimentarias (documento base para discusión). Roma: FAO.

Hatchwell E. and S. Calder. (1995). Cuba in Focus: A guide to the People, Politics and Culture. London: Latin America Bureau. 
IFAD. (2006). Targeting Reaching the Rural Poor. IFAD Strategy for rural poverty reduction in Latin America and the Caribbean. Rome: IFAD.

Madeley, J. (2002) Food for All: the Need for a New Agriculture. Dhaka: University Press LTD and London and New York: Zed Books.

Martin, L. (2002) Transforming the Cuban countryside: property, markets, and technological change. In Funes, F., García, L., Bourque, M., Rosset, P. (eds.), Sustainable agriculture and resistance: transforming food production in Cuba (pp-57-71).Oakland: Food First Books.

Martínez-Viera, R. (1997). Los biofertilizantes como pilares básicos de la agricultura sostenible en Cuba. Trabajo presentado en el I Taller Nacional de Producción Agroecológica de Cultivos Alimenticios en Condiciones Tropicales, La Habana, Cuba.

Martínez-Viera, R. y Hernández, G. (1995). Los biofertilizantes en la agricultura cubana. Trabajo presentado en el III Encuentro Nacional de Agricultura Orgánica. La Habana, Cuba.

Mesa-Lago, C. (1998). Assessing Economic and Social Performance in the Cuban Transition of the 1990s. World Development, 26 (5), 857-876.

MINAGRI. (2011). Datos básicos. Ministerio de la Agricultura, La Habana, Cuba.

Nova, A. (1993). Cuba: ¿Modificación o transformación agricola?. La Habana, Cuba: CEEC.

Nova, A. (2001). Cuba: Hacia una agricultura sustentable. Revista CUBA: Investigación Económica, INIE, 4, OctubreDiciembre.

Nova, A. (2006). La agricultura en Cuba: evolución y trayectoria 1959-2005. La Habana: Editorial Ciencias Sociales.

Nova, A. (2013). Un nuevo modelo cubano de gestión agrícola. Temas, 77, 84-91.

Nova, A. y González, M. (2015). Cuba's Agricultural Transformations. Journal of Agricultural Studies, 3(2), 175-193.

ONE. (1996). Anuario estadístico de Cuba. Recuperado de la Oficina Nacional de Estadísticas de Cuba: http://ww w.one.cu

ONE. (2000). Anuario estadístico de Cuba. Recuperado de la Oficina Nacional de Estadísticas de Cuba: http://ww w.one.cu/

ONE. (2007). Panorama uso de la tierra. Recuperado de la Oficina Nacional de Estadísticas de Cuba: http://www. one.cu/

ONEI. (2009). Anuario estadístico de Cuba. Recuperado de la Oficina Nacional de Estadísticas de Cuba: http://ww w.one.cu/

ONEI. (2016). Anuario estadístico de Cuba. Recuperado de la Oficina Nacional de Estadísticas de Cuba: http://ww w.one.cu/

Ortega-Cerdà, M. y Rivera, M. (2010). Indicadores internacionales de soberanía alimentaria. Revista Iberoamericana de Economía Ecológica, 14, 53-77.

PCC. (abril, 2011). Lineamientos de la Politica Económica y Social del Partido y de la Revolución. VI Congreso del Partido Comunista de Cuba, La Habana, Cuba. Recuperado de http://www.cuba.cu/gobierno/documentos/2 011/esp/1160711i.pdf.

PESA-FAO. (febrero, 2011). Seguridad Alimentaria Nutricional, Conceptos Básicos. 3ra Edición. Honduras: Proyecto Food Facility.

Ríos, A. y Aguerrebere, S. (1998). La tracción animal en Cuba. Trabajo presentado en el Evento Internacional Agroingeniería. La Habana, Cuba.

Rodríguez, J.L. (2016). Una mirada a la economía cubana y sus perspectivas en 2016. Actualización del modelo socialista cubano. Recuperado de http://www.cubadebate.cu/opinion/2016/04/28/una-mirada-a-la-economia-cubana-y -sus-perspectivas-en-2016/\#.WCQ3m_nhDIU (17 de mayo de 2016).

Rodríguez-Ojea, A., et al., (2001). The Nutrition Transition in Cuba in the Nineties: an Overview. Public Health Nutrition, 5(1), 129-133.

Rosset, P. (2011). Food Sovereignty and Alternative Paradigms to Confront Land Grabbing and the Food and Climate Crises. Development, 54(1), 21-30. 
Rosset, P. and Benjamin, M. (1994). The greening of the revolution: Cuba's experiment with organic agriculture. Melbourne: Ocean Press.

Third World Network and IFAD. (2006). Globalization, Liberalization, and Protectionism: Impacts on Poor Rural Producers in Developing Countries. Rome: IFAD.

Vía Campesina. (2002). Food Sovereignty. Flyer distributed at the World Food Summit +5, Rome, Italy. Recuperado de https://viacampesina.org/en/index.php/main-issues-mainmenu-27/food-sovereignty-and-trade-mainmenu -38/398-declaration-ngo-forum-fao-summit-rome5 (02 de mayo de 2016)

Wright, J. (2005). ¡Falta petróleo! Cuba's experiences in the transformation to a more ecological agriculture and impact on food security. (PhD thesis), Wageningen University, Wageningen, Netherlands.

\section{Notas}

1 Este artículo se basa en una investigación financiada por la Fundación EU-LAC (2015-2016) y presenta parcialmente algunos contenidos del informe final diseñado para asesorar políticas agrarias y rurales en América Latina y la Unión Europea. Agradezco enormemente los comentarios proporcionados por los diferentes participantes en el encuentro preparatorio y en la sesión $n^{\circ} 14$ del XII Congreso de la Asociación Española de Historia Económica, El ascenso del sistema alimentario moderno (1870-presente): economía, empresa y ecología, celebrados en Zaragoza el 10 de mayo y en Salamanca el 7 de septiembre 2017.

2 Según Deere (1992), a finales de la década de 1980, de los principales 13 productos de consumo nacional (que representaban el $75 \%$ del valor de las importaciones de alimentos) la antigua Unión Soviética proporcionaba el 50 $\%$ o más del tonelaje de 9 de ellos, lo que incluía el $100 \%$ de la harina de trigo, la leche condensada y el pescado y el $89 \%$ del trigo. Al mismo tiempo, Bulgaria proporcionaba el $29 \%$ del queso, el $20 \%$ de manteca y el $4 \%$ de la carne enlatada. Alemania oriental suministraba el $6 \%$ de la manteca y mantequilla importada durante esos años, además de una proporción importante de la leche en polvo.

3 CONSEJO DE AYUDA MUTUA ECONÓMICA, en occidente denominado COMECON fundado en 1949. Formado por los países satélites de la Unión Soviética tras la II Guerra Mundial: Bulgaria, Checoslovaquia, Hungría, Polonia, Rumanía, Albania y la U. Soviética desde 1949; posteriormente Alemania Oriental (1950), Mongolia (1962), Cuba (1972) y Vietnam (1978). Durante la década de 1960 fue el experimento de integración económica del campo socialista caracterizado por el bilateralismo de sus miembros con la Unión Soviética más que por el multilateralismo entre ellos.

4 Los datos de la FAO para Cuba provienen de las siguientes fuentes: el sistema de racionamiento, la comida vendida a precios subsidiados en instituciones públicas como comedores sociales en empresas, colegios, enfermerías, cafeterías y estands; la comida distribuida en hospitales y ambulatorios; los alimentos producidos en parcelas urbanas y rurales de autoabastecimiento vendidas por los trabajadores o productores y la comida comprada en otros mercados paralelos (food outlets) (Álvarez, 2004; FAO, 2009).

5 Durante los peores años de la crisis, los únicos alimentos disponibles eran azúcar, arroz, raíces y tubérculos (Wright, 2005). La mortalidad aumentó entre los ancianos, la incidencia de tuberculosis fue dramática debida a la desnutrición y las condiciones insalubres de vivienda (Mesa-Lago, 1998; Wright, 2005). La neuritis óptica asociada a los bajos niveles de vitamina B1 afectó a 50.000 personas entre 1993 y 1994, 20.000 de las cuales se quedaron ciegas (Hatchwell y Calder, 1995).

6 La Vía Campesina es un movimiento internacional nacido en 1993 que agrupa a millones de campesinos y campesinas, pequeños y medianos productores, pueblos sin tierra, indígenas, migrantes y trabajadores agrícolas de todo el mundo. Defiende la agricultura sostenible a pequeña escala como un modo de promover la justicia social y la dignidad. Se opone firmemente a los agronegocios y a las multinacionales. La Vía Campesina agrupa a más de 164 organizaciones locales y nacionales en 73 países de África, Asia, Europa y América y representa a alrededor de 200 millones de campesinos y campesinas. Para más información: https://viacampesina.org/es/.

7 Los estudios desarrollados desde el trabajo original de Goldschmidt (1978) confirman estas tendencias en la actualidad

8 Por ejemplo, los beneficios de diferentes fertilizantes biológicos como Rhizobium, que en 1995 substituyó el 75-80 \% de los fertilizantes nitrogenados empleados en los frijoles y Bradyrhizobiumque reemplazó el 80 \% de dichos fertilizantes químicos en la soja y las leguminosas forrajeras (Martínez-Viera,1997; Martínez-Viera and Hernández, 1995).Los grupos de bueyes eran más baratos, no compactan la tierra y se podían usar en la estación lluviosa frente a los tractores, además de proporcionar fertilizantes orgánicos (Funes-Monzote, 2008). Entre 1989 y 1997 el uso de los bueyes aumentó de 163.000 a 400.000 (Funes, 2002; Ríos y Aguerrebere, 1998). 
9 La media de cada país o región del suministro de kcal disponibles para el consumo se normaliza con la media de los requerimientos de energía de la dieta estimada para su población, y se obtiene un índice de suficiencia del suministro de alimentos en términos de kcal.

10 Este indicador se calcula comparando la distribución de probabilidad del consumo de energía habitual diario con un umbral denominado mínimo de requerimientos energéticos. Ambos se basan en la noción de un individuo medio en la población de referencia. Para más información y detalle sobre todos los indicadores de la SAN de la FAO: http://w ww.fao.org/economic/ess/ess-fs/indicadores-de-la-seguridad-alimentaria/es/\#.WWijwojyjIU. Última actualización de la base de datos el 16/12/2016.

$11 \mathrm{La}$ intensidad del déficit alimentario se estima como la diferencia entre los requerimientos medios de energía y el consumo de energía medio de la población desnutrida (food-deprived) se multiplica por el número de desnutridos para proporcionar una estimación del déficit alimentario total de un país, que se normaliza entonces con la población total.

12 No existen datos disponibles para la densidad de carreteras, el índice nacional de precios de los alimentos ni el porcentaje del gasto de los alimentos de los pobres.

13 Se calcula como (importaciones de cereales - exportaciones de cereales) / (producción de cereales + importaciones de cereales - exportaciones de cereales) ${ }^{*} 100$. Si se tiene en cuenta esta fórmula, el indicador solo asume valores $<=100$. Valores negativos indican que el país es un exportador neto de cereales.

14 Los resultados de las diversas instituciones científico-técnicas existentes como la Asociación Cubana de Agricultura Orgánica desde 1993 y la Asociación Cubana de Técnicos Agrícolas y Forestales (ACTAF) a partir de 1999, el programa de campesino a campesino de la ANAP, el fitomejoramiento participativo y el programa de innovación agropecuaria Local del INCA, de la Universidad de La Habana, y la agricultura urbana y suburbana muestran dicho potencial. 